\title{
Resistencia y luchas femeniles. La Unión Nacional de Mujeres Mexicanas en el verano del 68: una historia desconocida
}

Women's Resistance and Struggles. The Unión Nacional de Mujeres

Mexicanas in the Spring of '68: an Untold History

\section{Verónica Oikión Solano \\ El Colegio de Michoacán voikions@gmail.com}

Recibido: 4 de mayo de 2018 - Aprobado: 15 de mayo de 2018

Cómo citar este artículo: Verónica Oikión Solano, "Resistencia y luchas femeniles. La Unión Nacional de Mujeres en el verano del 68: una historia desconocida", en Legajos. Boletín del Archivo General de la Nación, núm. 17 (septiembre-diciembre 2018), pp. 55-84.

\section{Resumen}

Con perspectiva de género abordo una historia desconocida en torno a la movilización de las mujeres durante el movimiento estudiantil de 1968. Nuestras protagonistas integraron la Unión Nacional de Mujeres Mexicanas, y su historia ha quedado verdaderamente sepultada bajo un caudal historiográfico apabullante sobre el movimiento de la juventud del 68. Pretendo visibilizar a las mujeres que también fueron actoras indiscutibles en el empuje democrático del parteaguas del 68 con el afán de descentrar la historia del periodo con énfasis en las mujeres, y hacer patente que a lo largo de la década de los sesenta la Unión Nacional de Mujeres Mexicanas dio a luz un activismo que refutó hasta donde pudo al Estado autoritario en su conjunto.

Palabras clave: Unión Nacional de Mujeres Mexicanas, movimiento estudiantil de 1968, luchas femeniles, posrevolución mexicana, imaginario de nueva izquierda

\section{Abstract}

From a gender perspective, this article examines the untold story of mobilizations by women during Mexico's 1968 student movement. Our protagonists belonged to the Unión Nacional de Mujeres Mexicanas (National Union of Mexican Women), an organization whose story has long been buried under the overwhelming flood of historiographical analyses of what is considered predominantly a youth movement. This article seeks to make visible women who were undeniably key actors in the wave of democratic fervor that swept the country in 1968 by decentering the history of the period, stressing the role of women, and establishing as historical fact that in the 1960s the Unión Nacional gave birth to an activism that denounced, as far as it could, the authoritarian State.

Keywords: Unión Nacional de Mujeres Mexicanas, student movement, women's struggles, postrevolutionary Mexico, imaginary of the new left 


\section{Preámbulo}

Mi intención es historiar la Unión Nacional de Mujeres Mexicanas (UNMM) durante el movimiento estudiantil de 1968. Para ello utilizo dos vías de acercamiento metodológico, que no van paralelas sino entrelazadas para dar cuenta más puntual de la aportación de la movilización de la unMm y su dimensión en el espectro político de la coyuntura del 68. Por un lado, me valgo de la perspectiva de género al pensar en ese colectivo femenil como tal y la agencia que logró construir, pero también en sus relaciones diferenciadas con los conglomerados masculinos, y, especialmente, con la visión autoritaria y el ejercicio varonil del poder político. Por el otro, recurro al repertorio de las formas de acción colectiva formulado por Tarrow, ${ }^{1}$ pero con un examen de género según lo propone Martínez Hernández, ${ }^{2}$ y que, en esencia, de acuerdo con Hernández Sandoica, ${ }^{3}$ se inscribe en el desigual reparto de poder entre los sexos.

Como antecedente de la UnMm aludo brevemente - en los dos primeros apartados - a la movilización femenil de los años treinta, cuarenta, cincuenta y principios de los sesenta. En seguida, explico cómo se logró articular la organización femenina para dar paso a la UNMM, con planteamientos maternalistas con sesgo político y social, ${ }^{4}$ antiimperialistas y pacifistas, y hasta dónde llegó su declarativa de liberación.

${ }^{1}$ Tarrow, El poder en movimiento, p. 178.

${ }^{2}$ Martínez Hernández, "Las formas de acción colectiva”, pp. 132 y 151-152.

${ }^{3}$ Hernández Sandoica, Tendencias historiográficas actuales, p. 443.

${ }^{4}$ La UNMM definió políticas maternalistas a partir de discursos, representaciones y prácticas que enlazaron el papel materno femenino. Se entiende el maternalismo como la noción que "identifica a las ideas y actitudes que encuentran predominantes y trascendentales las responsabilidades femeninas frente a la maternidad. Aunque esta posición constituye un aspecto central en las sociedades patriarcales, en gran medida impregnó a las feministas del siglo XIX y buena parte del siglo XX. Algunas autoras se han referido a esta compenetración con los valores de la maternidad [como] un punto angular en la reivindicación de los derechos femeninos". Aunque se subraya la paradoja acerca de que "resultan poco conciliables los mandatos obligatorios de la maternidad con la autodeterminación femenina que puede renunciar a la reproducción”. Véase Barrancos, "Maternalismo”, pp. 207-208. 
A continuación, me concentro en el papel destacado que tuvo la Unión Nacional de Mujeres Mexicanas en el verano del 68, cuya representación sigue, en la actualidad, bastante ignorado. Este desconocimiento se debe a que la abultada historiografía de la movilización juvenil generalmente ha dejado de lado la resistencia de las mujeres en dicha coyuntura - estudiantes, brigadistas, maestras, madres de familia, trabajadoras, intelectuales, artistas, etcétera - al reproducirse un discurso historiográfico con un acento masculinizado sobre el movimiento.

En este tenor indago si su resistencia y sus luchas - como parte de su imaginario social de izquierda - tuvieron efectos en el impulso de una ciudadanía femenil de nuevo cuño al modificar sus prácticas sociales y de género en relación con los grupos masculinos de izquierda con los cuales confraternizaban; así como al desencajar el papel tradicional femenino de escasa presencia en el ámbito público y político. No sólo para actuar decididamente en la movilización estudiantil e interpelar la figura presidencial autoritaria, sino también para expresar demandas específicas de género cuya esencia democrática y emancipatoria pone en evidencia la larga ruta que aún hoy en día recorren los núcleos femeniles en su impugnación contra el Estado con predominancia masculina, y sus viejas prácticas y representaciones opresivas contra las mujeres.

\section{Las organizaciones femeniles: antecedentes}

La integración de la Unión Nacional de Mujeres Mexicanas fue resultado de la movilización de las mujeres de izquierda. Su antecedente emblemático en la primera mitad del siglo xx fue el Frente Único Pro Derechos de la Mujer (FUPDM), hegemonizado por mujeres comunistas, y entre cuyos principales objetivos estuvo la reforma constitucional para el reconocimiento de la plena ciudadanía femenil y sus derechos políticos. Al no concretarse dicha reforma, el FUPDM acabó por diluirse y desaparecer a inicios de los años cuarenta. ${ }^{5}$

${ }^{5}$ Oikión Solano, Cuca García (1889-1973), por las causas de las mujeres y la revolución, pp. 249 y ss. 
$\mathrm{Al}$ avanzar esa década, y a instancias del Partido Comunista Mexicano (PCM), surgió el Bloque Nacional de Mujeres Revolucionarias (BNMR), que tuvo una actuación muy limitada y no logró rearticular la masiva movilización femenil de la década antecedente.

A principios de los años cincuenta, de nueva cuenta el PCM llamó a la integración de su sector femenino en una nueva organización denominada Unión Democrática de Mujeres Mexicanas (UDMM), que tuvo una mayor presencia nacional y, sobre todo, una ligazón más determinante con la Federación Democrática Internacional de Mujeres (FDIM) ${ }^{6}$ la coalición femenil más relevante de la izquierda procomunista, fundada por las mujeres francesas de izquierda en 1945 con el afán de unificar, bajo criterios maternalistas, antifascistas y pacifistas, a los contingentes femeniles de todo el mundo. Muy pronto la FDIM se adscribiría de distintas maneras al bloque soviético y sería un factor de intermediación política ${ }^{7}$ femenil en el contexto de la posguerra y desde luego en el marco de las tensiones bipolares de la Guerra Fría. ${ }^{8}$

En el México de los años cincuenta y principios de los sesenta, paralelamente al accionar de la UnMM, se constituyeron otras organizaciones, como Vanguardia de la Mujer Mexicana (VMM) — con un perfil de mujeres intelectuales y pertenecientes al sector educativo- y el Comité Permanente Pro-Congresos Latinoamericanos de Mujeres (CPPCLM).

La organización VMM destacó por su solidaridad con el movimiento magisterial y con otras luchas sociales del periodo, sobre todo la de los ferrocarrileros. Entre sus líderes descollaron la artista plástica

${ }^{6}$ Oikión Solano, "Mujeres comunistas en México. Desigualdad social y lucha política, 1935-1955”, pp. 153-172.

${ }^{7}$ La trascendencia de la FDIM se evidenció al instituirse como miembro consultivo de la Organización de Naciones Unidas (ONU) y de la UnESCO, su organismo para la educación, la ciencia y la cultura.

${ }^{8}$ Para conocer más en detalle la historia de la FDIM, véase Pieper Mooney, "El antifascismo como fuerza movilizadora: Fanny Edelman y la Federación Democrática Internacional de Mujeres (FDIM)", pp. 207-226, y De Haan, "La Federación Democrática Internacional de Mujeres (FDIM) y América Latina”, pp. 17-44. 
Mercedes Quevedo, con militancia comunista, y la eminente arqueóloga Eulalia Guzmán. A pesar de que el ideario social de vmm incluía demandas que venía planteando el movimiento de mujeres desde la primera mitad del siglo xx, no tuvo fuerte impacto ni repercusión masiva entre sectores femeniles amplios. ${ }^{9}$

Por su parte, el CPPCLM, también llamado Comité Preparatorio de los Congresos Latinoamericanos de Mujeres o Comité Permanente Pro Congresos Latinoamericanos de Mujeres estuvo encabezado por la universitaria Clementina Batalla de Bassols. ${ }^{10}$

En abril de 1960 Batalla de Bassols representó al Comité Preparatorio en su estancia en Copenhague al asistir al Congreso Internacional de Mujeres (CIM), que subrayó las "Tareas de las asociaciones femeninas y de todas las mujeres en favor de la distensión internacional, el desarme y la cooperación entre los pueblos", acorde con el espíritu pacifista de la FDIM. Asimismo, Batalla de Bassols, a su regreso a

${ }^{9}$ Jiménez, Reyes, Sembradoras de futuros, pp. 80-81 y 83-84.

${ }^{10}$ Clementina Batalla Torres de Bassols nació en Acapulco el 17 de octubre de 1894 y falleció el 8 de noviembre de 1987 en Guadalajara. Fue hija del antiporfirista Diódoro Batalla. Obtuvo en la Universidad Nacional su título de licenciada en Derecho en 1920, con una tesis sobre el trabajo de la mujer en México. En ese mismo año se casó con su compañero de estudios Narciso Bassols, quien tuvo numerosos cargos públicos y su trayectoria fue muy reconocida. En 1959, Bassols falleció en un accidente. Su viuda, que toda su vida de casada se dedicó exclusivamente al hogar y a la atención de sus hijos, dio un vuelco en sus actividades y se convirtió en una gran defensora de las mujeres. Viajó por todo el mundo con el ánimo de proyectar la militancia femenil mexicana en el plano internacional con equidad de género. Revísense las memorias de Batalla de Bassols con los títulos "Mi vida", "Revolución mexicana", y "Actividades políticas y sociales mías a partir de 1959. A la muerte de mi marido", Archivo General de la Nación-México (en adelante AGN), Colección Clementina Batalla de Bassols (en adelante CCBB), caja 1, exp. 8. El Programa de Historia Oral dirigido por las historiadoras Alicia Olivera de Bonfil y Eugenia Meyer, cuenta con una entrevista realizada por ellas mismas a Batalla de Bassols, los días 20 y 28 de febrero y 14 de marzo de 1973 en la Ciudad de México. El acervo sonoro de dicha entrevista está resguardado en la Biblioteca del Museo Nacional de Antropología e Historia del INAH, con la clasificación PHO/4/13. También los historiadores Wilkie, James y Edna, la entrevistaron el 8 de abril y el 6 de mayo de 1964. Véase http://wrerw.profmex.org/mexicoandtheworld/volume13/4fall08/clementina. 
México, emprendió tareas de divulgación en la Ciudad de México y fuera de la capital de la República sobre lo acordado en el CiM. ${ }^{11}$

Al igual que vmm, el Comité Preparatorio se pronunció por la organización unitaria. Ambos grupos, al coincidir en este postulado, llevaron a cabo acciones conjuntas, secundados por otras agrupaciones, como el Comité Coordinador Femenino para la Defensa de la Patria (CCFPDP), surgido en 1940, en favor de la paz mundial y en contra del conflicto bélico que agobiaba al planeta, ${ }^{12}$ así como la UDMM y el llamado Congreso de Universitarias.

Debo destacar que el Comité Preparatorio funcionó de cara a construir una red latinoamericana de solidaridad femenil mediante su inserción y acción política directa en el Movimiento de Liberación Nacional (MLN), nacido como "un frente amplio de activistas nacionalistas y de izquierda socialista que no pretendía definirse como único, ni clasista, ni vinculado a línea partidaria alguna", con un ideario

html La figura de Batalla de Bassols, pero sobre todo sus memorias, fueron objeto de la tesis de licenciatura inédita en Historia de Guadalupe Belem Bustamante Méndez, titulada "Las memorias de Clementina Batalla de Bassols (1894-1987). Pensamientos tomados de aquí y allá y recuerdos de mi vida". Esta tesis se avoca a exponer las memorias de Batalla únicamente como una autobiografía con un enfoque lineal. Su análisis me parece limitado. No percibe la importancia de la personalidad pública de Batalla de Bassols en el movimiento de las mujeres.

11 "Carta de Esther Brinch, a nombre del Comité Internacional de Enlace [establecido luego de la realización del Congreso Internacional de Mujeres], a Clementina Batalla de Bassols", Copenhague, 26 de mayo de 1960, en AGN, CCBB, caja 1, exp. 12, f. 1, y "Cartas de Clementina B. de Bassols a Anna Westergaard, del Comité Internacional de Iniciativa a la Reunión de Mujeres en Copenhague", México, 13 de junio de 1960 y 8 de agosto de 1960, en AGN, CCBB, caja 1, exp. 12, ff. 66 y 67. En dichas misivas Batalla consignó: "La tarea de dar a conocer lo hecho en el Encuentro lo tomo como una responsabilidad adquirida frente al empeño, entusiasmo y resolución con que las 900 mujeres reunidas en Copenhague manifestamos la firme voluntad de no cejar en nuestros trabajos, en bien de la Humanidad, y a favor de la Paz”. Para ello dictó conferencias, publicó artículos y aceptó entrevistas.

${ }^{12}$ Véase Oikión Solano, Cuca García, p. 335. 
social y económico de carácter nacionalista y reformista. También en el MLN hubo presencia de vMM. ${ }^{13}$

Recuérdese que la fundación del MLN, en agosto de 1961, derivó de la Conferencia Latinoamericana por la Soberanía Nacional, la Emancipación Económica y la Paz, realizada en la Ciudad de México en marzo de 1961, bajo los auspicios de distinguidas personalidades de la izquierda latinoamericana, que propugnaban por una lucha organizada de los pueblos de la región en contra del imperialismo estadounidense. La figura mexicana que tuvo la presencia más relevante fue, sin duda alguna, la del exmandatario michoacano Lázaro Cárdenas del Río. ${ }^{14}$

El discurso de Clementina Batalla de Bassols, pronunciado durante la celebración de la Conferencia, fue a nombre del Comité Preparatorio; también lo expuso representando a VMM, el CGFPDP y la UDMM. ${ }^{15}$

Esta fue la plataforma política para el desempeño de Batalla de Bassols en sucesivos encuentros femeniles al lado de otras brillantes

${ }^{13}$ Jiménez, Reyes, Sembradoras de futuros, pp. 88-89 y Nava Hernández, "El cardenismo en Michoacán”, p. 469.

${ }^{14}$ Oikión Solano, "El Movimiento de Liberación”, p. 31.

${ }^{15}$ Véase el discurso de Batalla de Bassols, dirigido al "Señor Presidente de la Conferencia Latinoamericana por la Soberanía Nacional, la Emancipación Económica y la Paz [y] Señores Delegados", Agn, cabB, caja 2, exp. 4, ff. 84-90. Dicho discurso también exhibe su postura igualitarista y la aspiración de construir un Estado socialista de bienestar para toda la población, pero especialmente para las mujeres: "Conscientes de sus responsabilidades, ejerciendo sus derechos, contribuyendo al desarrollo de la técnica, de la ciencia y la cultura, conciliando sus actividades dentro y fuera del hogar [...] se sugirieron métodos de trabajo colectivo, que descansan en la ratificación de convenios, en la obligación impuesta a los Estados de dar a las mujeres de todos los países total igualdad económica, igual participación en la vida pública, acceso a todas las carreras y empleos con las mismas remuneraciones que el hombre, amplias reformas al derecho de la familia para fortificar las actividades dentro y fuera del hogar; y garantizar que las vidas que las mujeres han dado, sus hijos, no queden en peligro de guerras que sólo tienen por objeto acrecentar las ganancias de los consorcios, ayudar a los fines colonialistas, destruir las culturas, avivar odios, desperdiciar fuerzas de hombres y mujeres, convertir nuestro planeta en un campo de destrucción y de ruina...”. 
intelectuales de izquierda, como Martha López Portillo de Tamayo, Sandra Maldonado, María Efraína Rocha, Elvira Trueba, Ana Mayés, Martha Bórquez y Adelina Zendejas. ${ }^{16}$

\section{El Comité Unificador Nacional de Mujeres, prolegómeno de la UNMM}

Se hablaba de constituir el Comité Unificador Nacional de Mujeres (CUNM) desde febrero de 1963. Al preparar la participación de los grupos femeniles en el Congreso Mundial de Mujeres organizado por la FDIM en Moscú, en junio de 1963, ya aparecían como CunM. ${ }^{17} \mathrm{Al}$ inicio de 1964, en el mes de enero, quedó formalizado dicho Comité mediante reuniones cuyos resolutivos acordaron constituirlo con la inclusión de tres representantes de cada grupo o sector, con la finalidad de que se realizara una distribución equitativa para colocar a una representante de cada grupo "en la Comisión Ejecutiva, la Comisión General de Sectores y en la Comisión General de Organización". En la directiva del Comité Unificador quedaron Batalla de Bassols, Martha Bórquez, Ana María Colín, Esthela Jiménez Esponda, Virginia Gómez Nieto, Margarita Nolasco y Martha López Portillo de Tamayo. ${ }^{18}$

${ }^{16}$ Jiménez, Reyes, Sembradoras de futuros, pp. 88-89 y 90-91. Oikión Solano, "El Movimiento de Liberación Nacional en Michoacán”, p. 11, y AGN, CCBB, caja 2, exp. 6, f. 3. ${ }^{17}$ En un reporte del aparato de control del Estado se le hizo seguimiento a la dirigencia del PCM, así como a una asamblea femenil del partido, en donde se acordó la preparación de una reunión para constituir el Comité Unificador Nacional de Mujeres, "que ya está funcionando en forma provisional”. Ahí se nombró además "una Comisión que se encargue de entrevistar a las dirigentes del 'Sector Femenil del MLN', 'Unión Democrática de Mujeres Mexicanas', 'Vanguardia de la Mujer Mexicana' y 'Comité de Economistas Mexicanas', organismos que constituirán el 'Comité Unificador Nacional de Mujeres". Reporte titulado "Partido Comunista Mexicano", sin firma, México, D.F., 28 de febrero de 1963, en AGn, fondo de la Secretaría de Gobernación, sección Dirección General de Investigaciones Políticas y Sociales (en adelante DGIPS), caja 2622, exp. 4, f. 100.

${ }^{18}$ Jiménez, Reyes, Sembradoras de futuros, p. 111. 
Con motivo del Día Internacional de la Mujer, el 8 de marzo de 1964, Batalla de Bassols hizo un pronunciamiento respecto de la configuración del Comité Unificador que en esa fecha lanzó un "Llamamiento a la Mujer Mexicana". ${ }^{19}$ Bassols precisó que la unidad femenil de izquierda ofrecía "inmensas posibilidades" para unir esfuerzos:

...en una fuerte organización nacional en torno a un programa que recoja nuestros más urgentes problemas [y] llama a las mujeres de todos los sectores, en toda la República para emprender el noble anhelo de la Unidad nacional y de la cooperación internacional. Como dice nuestro "Llamamiento": no para ir en contra de nadie sino en favor de todas, para actuar dentro de nuestra Constitución y lograr con el esfuerzo colectivo, el cumplimiento de las leyes que reconozcan nuestros derechos y la expedición de nuevas que en el momento actual se necesitan para atender y dignificar nuestra condición de mujeres; no para ponernos al margen de nuestros derechos, sino para ejercer[los] diaria [e] incansablemente. ${ }^{20}$

Batalla de Bassols cerró su alocución colmada de un imaginario igualitario y pacifista, aunque mediado por una fuerte carga nacionalista y de unidad nacional que apelaba al ordenamiento de la Carta Magna para su actuar colectivo y en espera de consolidar sus derechos, aunque sin cuestionar esos parámetros jurídico político androcéntricos. A la

${ }^{19}$ Jiménez, Reyes, Sembradoras de futuros, p. 115.

${ }^{20}$ En su posicionamiento, Clementina Batalla, además de reiterar la unidad interna "tan necesaria para presentar un frente común que nos dé fuerza y conciencia colectiva", explicó que la unidad internacional era conveniente para hacerse oír de los organismos internacionales. Reafirmó la necesidad de "igualdad entre hombres y mujeres y plena participación de todos en la vida económica, social y política de los pueblos". "Discurso de Clementina B. de Bassols con motivo del Día Internacional de la Mujer", 8 de marzo de 1964, AGN, CCBB, caja 2, exp. 2, f. 74. 
vez también expresó su solidaridad con las mujeres del planeta: "Nos une nuestra voluntad de Paz, de Justicia, de progreso y dicha para la Humanidad [...] con el fin de que podamos vivir y luchar por una existencia mejor en un mundo sin armas y sin bombas, un mundo de Paz". ${ }^{21}$

Finalmente, se definieron las fechas del 9, 10 y 11 de octubre de ese año de 1964 para efectuar el Congreso Femenil de Unidad. ${ }^{22}$

\section{La Unión Nacional de Mujeres Mexicanas: plataforma política y de género}

En el Congreso de la unidad femenil participaron mujeres de distintos sectores sociales de toda la República: campesinas, ejidatarias, estudiantes, amas de casa, maestras, enfermeras, trabajadoras fabriles y de distinto rango, maestras, profesionistas, escritoras, intelectuales, mujeres universitarias de la UNAM, del Instituto Politécnico Nacional (IPN) y de las Escuelas Normales. No todas sus integrantes militaron en el PCM o en el Partido Popular Socialista (PPS), y al incorporarse cientos de mujeres sin militancia también permitió al organismo femenil abrirse con mayor libertad a la sociedad, sin consignas ni líneas estratégicas partidistas masculinas verticales que las limitaran en su actuar colectivo y social, y con un ideario que destacó permanentemente la organización y el accionar en el colectivo como los ejes claves de su funcionamiento, es decir, las mujeres en un fluir social constante, que pretendió centrar sus aspiraciones y necesidades específicas en sus luchas de emancipación, aunque siempre con la concurrencia de los hombres trabajadores, con un sentido de movimiento femenino igualitario. A la vez, las mujeres de la UnMm se reconocieron como de izquierda, con posturas progresistas y de cambio social. ${ }^{23} \mathrm{Al}$ insertarse en esa dinámica modificaron su percepción del mundo y al cobrar

21 "Discurso de Clementina B. de Bassols con motivo del Día Internacional de la Mujer", 8 de marzo de 1964, AGN, CGBB, caja 2, exp. 2, f. 76.

${ }^{22}$ Jiménez, Reyes, Sembradoras de futuros, p. 117.

${ }^{23}$ Jiménez, Reyes, Sembradoras de futuros, pp. 119-120, 138 y 143. 
conciencia de su entorno social desafiaron el orden tradicional de género con predominancia masculina que les impedía asumirse como protagonistas de la historia.

Las sesiones del Congreso fundacional se realizaron bajo la consigna: “¡Por nuestra liberación y la paz!”. Bajo este lema las mujeres aglutinadas en la UnMM se asumieron como sujetos sociales con idearios pacifistas y con un fuerte compromiso por la paz del mundo con una visión transnacional. De tal manera apoyaron distintas causas en relación con las movilizaciones sociales y políticas de la década. Fue notoria su adhesión a la Revolución cubana. Para consolidar este bagaje la organización suscribió una declarativa nacionalista, antimilitarista, soberanista y antiimperialista:

Apoyar la tradicional política mexicana de pleno respeto a la soberanía y libre autodeterminación de los pueblos; apoyar todas las iniciativas y acciones que se realicen para conseguir la suspensión de todas las pruebas nucleares; el desmantelamiento de todas las bases militares en territorios extranjeros y la anulación de los pactos militares; apoyar la política de coexistencia pacífica y por el desarme general y total; apoyar las luchas de las mujeres y los pueblos por su liberación, contra el imperialismo, el colonialismo y el neocolonialismo; ampliar y fortalecer los lazos de amistad y solidaridad con las mujeres de todo el mundo; luchar porque tanto en las escuelas como en los hogares se eduque a nuestros niños en un espíritu de amor a la paz, a la comprensión y amistad entre todos los pueblos del mundo. ${ }^{24}$

Así, la UNMm quedó incorporada a la FDIM como su sección mexicana, dando un paso en las relaciones transnacionales establecidas. El intenso intercambio entre la FDIM y la UNMM logró proyectarla

${ }^{24}$ Jiménez, Reyes, Sembradoras de futuros, pp. 123 y 145. 
en el plano latinoamericano y mundial en su activismo feminista de izquierda. De igual manera, la FDIM - como "organización paraguas" - apoyó decididamente las demandas perfiladas por la UnMM. ${ }^{25}$

En el plano interno, la UNMM instituyó sus órganos de dirección mediante su Congreso nacional, su consejo directivo nacional (con 33 miembros) y el secretariado (integrado por un número fijado por el consejo de dirección), con la prerrogativa para elegir la presidencia, las vicepresidencias y las secretarías. En los espacios estatales, la dirigencia se depositaría en la asamblea estatal, regional o municipal con la participación de los comités de mujeres integrados por grupos sectorizados u organismos femeniles de la población. Contó con su órgano de difusión Mujeres Mexicanas, y fue importante porque en su contenido validaron distintas campañas en favor de las mujeres y la infancia; éstas fueron objetivos preponderantes a los que se les dio gran realce y difusión, y siempre en conexión con los llamamientos internacionales de la FDIM. ${ }^{26}$

El programa de la UNMM - desproporcionado en relación con lo que efectivamente podría realizar en las condiciones reales del país en ese periodo — ${ }^{27}$ se pronunció por "mejorar las condiciones de vida

${ }^{25}$ De Haan define a la FDIM como una "organización paraguas" en la medida en que apoyó las luchas sociales a las que se enfrentaron sus organizaciones afiliadas en Latinoamérica y en el resto del mundo, permitiéndoles "entender los vínculos entre sus luchas y crear modelos de solidaridad entre ellas". El acercamiento a la FDIM, como lo propone esta autora, debería tener "un énfasis en la interconexión de sus distintas dimensiones: nacional, continental y global". De Haan, "La Federación Democrática Internacional de Mujeres (FDIM) y América Latina", p. 41. En 1967, la FDIM incorporó a la UnMm como miembro de su Consejo Directivo.

${ }^{26}$ Jiménez, Reyes, Sembradoras de futuros, pp. 124, 145, 149, 150 y 157. La Unmm creó una Comisión de la Infancia. Por ejemplo, en marzo de 1966 se realizó la Jornada Nacional en Defensa del Niño, y en 1967 se llevó a cabo una Campaña Nacional Proguarderías Infantiles iniciada bajo la cobertura de una Jornada de la Infancia.

${ }^{27}$ Constantemente se hicieron llamados a los comités para que se apoyara a la organización, que frecuentemente tuvo problemas económicos por la falta de recursos. Para solventar las carencias se realizaron regularmente distintos eventos y actividades sociales (cine clubs, festivales, exposiciones cuyas obras eran donadas por los artistas, jornadas de solidaridad, etcétera). 
de la mujer mexicana", y, por tanto, para cumplir con tal objetivo se estipularon varios ejes de lucha que a su vez se desglosaron según su naturaleza e importancia: "Por un mejor nivel de vida". Protección eficaz de la salud. "Por la igualdad de los derechos de la mujer en la sociedad y en la familia", en su condición de trabajadora, madre, campesina e indígena. Por una educación e igualdad de oportunidades a las niñas y los niños, así como contra la explotación del trabajo infantil. ${ }^{28}$ Por el establecimiento en México de "un régimen de verdadera democracia" para reconocer el estatuto pleno de las mujeres como ciudadanas. ${ }^{29}$

El diagnóstico de Batalla de Bassols en el primer Congreso de la UnMm, en septiembre de 1967, confirmó - ante el drama de las mujeres en México - la urgencia de:

\begin{abstract}
Movilizarse, organizarse, unirse, luchar. Nuestra lucha se inscribe en la del pueblo mexicano, es una parte integrante e importante de la lucha por la democracia sindical, contra la represión en el campo, porque se abra cauce a todas las corrientes de opinión en un proceso electoral que no sea una farsa sino auténticamente democrático; porque no se persiga y encarcele a los estudiantes, campesinos, intelectuales y aún mujeres, pues por primera vez en la historia del México moderno, hay mujeres como presas políticas [...]. Luchar por nuestros derechos es incorporarnos a las mejores luchas del pueblo mexicano y [es] nuestro deber inmediato. ${ }^{30}$
\end{abstract}

\footnotetext{
${ }^{28}$ Jiménez, Reyes, Sembradoras de futuros, pp. 119-123.

${ }^{29}$ Jiménez, Reyes, Sembradoras de futuros, p. 122.

30 "Informe General al Primer Congreso Nacional Ordinario de la Unión Nacional de Mujeres Mexicanas", AGN, CCBB, caja 2, exp. 4, f. 40.
} 
En esta tesitura, con el fin de acelerar la movilización femenil, con perfil incluyente y democratizador, la presidenta de la UNMM propuso "organizar comités de lucha para resolver los problemas más urgentes que haya en cada localidad", mostrando con esta determinación una intención real por acrecentar la fuerza femenil en acciones colectivas que dieran visibilidad a sus estrategias de género. Y aseguró que:

Todas las formas de organización, desde las más sencillas a las más formales, son válidas y todos los problemas exigen nuestra atención [...], pero los comités locales no pueden ocuparse únicamente de los problemas locales, porque también hay problemas nacionales en los que, para tratar de resolverlos, todas debemos trabajar coordinadamente y al mismo tiempo. ${ }^{31}$

Su discurso fue inclusivo y participativo al proponer una lucha encabezada por las mujeres en los escenarios locales y al ras del pueblo, pues ya contaba con grupos en más de la mitad del país, y con el respaldo de sus compañeros varones en distintos ámbitos: laborales, sindicales, rurales, escolares, académicos, intelectuales, artísticos, etcétera. Y justificó la lucha femenil con un sesgo nacionalista e integrador, en tanto que, al defender los derechos femeninos, la unMm afirmaba adherirse a las causas legítimas del pueblo mexicano.

Pero también su plataforma política tuvo un mirador mundial para solidarizarse con las luchas en distintos puntos del planeta contra el imperialismo y en favor de la descolonización. En consonancia con las posturas de la FDIM, Clementina Batalla, a nombre de la UnMm, declaró su adhesión a los pronunciamientos de Bertrand Russell, quien en 1968 arengaba a los líderes mundiales a formar un tribunal de crímenes de guerra, "con el fin de enjuiciar los cometidos

31 "Informe General al Primer Congreso Nacional Ordinario de la Unión Nacional de Mujeres Mexicanas”, AGN, CCBB, caja 2, exp. 4, ff. 49 y 50. 
contra el pueblo de Vietnam”. En ese marco, la UnMM, en voz de su presidenta, estaba plenamente convencida:

\begin{abstract}
De que solamente en un mundo de Paz podemos alcanzar la felicidad humana, [...]. Luchamos en el terreno internacional, $[\ldots]$ por el fin de la guerra en el Vietnam, por el respeto a las naciones latinoamericanas, sin el menoscabo de su dignidad; por una ayuda cada vez mayor a los pueblos de África y Asia; por la extinción del apartheid, baldón e ignominia de la Humanidad [...] y por la discriminación racial en los Estados Unidos de Norte-América. ${ }^{32}$
\end{abstract}

Al reprobar las prolongadas desigualdades fomentadas por el entramado económico del capitalismo mundial, así como los escenarios bélicos impuestos por la guerra fría, las mujeres de la UNMM debieron asumir consecuentemente su adhesión al movimiento estudiantil de 1968.

\title{
En las calles, en el verano del 68
}

La UNMM mantuvo confraternidad con organismos afines a su activismo social y político. Especialmente estableció una interrelación y un vínculo con asociaciones estudiantiles, y se solidarizó con sus luchas. Así lo hizo con la Central Nacional de Estudiantes Democráticos (CNED), ${ }^{33}$ la Federación de Estudiantes Campesinos Socia-

\footnotetext{
${ }^{32}$ Palabras de Clementina Batalla de Bassols dirigidas al "Honorable presídium, amigos y compañeros queridos", México, D.F., 25 de julio de 1968, con motivo de la sesión de clausura del Seminario de México, América Central y el Caribe sobre "La Defensa de los derechos de la mujer y del niño a la vida, al bienestar y a la educación", patrocinado por la unESCO a instancias de la FDIM, efectuado en la Ciudad de México los días 22 al 25 de julio de 1968, con la asistencia de la señora Cécile Hugel, secretaria general de la FDIM, AGN, CCBB, caja 2, exp. 2, f. 118.

${ }^{33}$ Véase Oikión Solano, "La Central Nacional de Estudiantes Democráticos", pp. 105-133.
} 
listas de México (FECSM), ${ }^{34}$ y grupos universitarios y de las escuelas normales de distintos puntos del país (todos ellos actuantes bajo el referente del PCM y otros núcleos de izquierda).

Debe destacarse que el movimiento estudiantil también fue de carácter popular por los contingentes de distintos sectores de la población que se agruparon en torno suyo. Y el ejemplo de esto es precisamente el involucramiento de la UNMM en el movimiento, cuyo accionar produjo la participación y la adhesión de gran número de mujeres. Los testimonios dan cuenta de cómo sus miembros se constituyeron en participantes activas en las manifestaciones, ${ }^{35}$ y su amplia dimensión explica el entrelazamiento de un gran cúmulo de sociabilidades femeninas.

${ }^{34}$ Concepción Mesa Montes se encargó de la Acción Femenil de la FEcSM y aseguró que: "nuestra participación en la UNMM es muy reciente, pero nos hemos dado cuenta de que se trata de que la UNMM tiene enormes perspectivas para desarrollarse, por ser ésta la única organización de su tipo en México, porque lucha por los derechos de la mujer y de todo el pueblo". Destacó también que institucionalmente en las Escuelas Normales del país había discriminación hacia las estudiantes, en vista de que existían 20 escuelas para varones y solo 9 para mujeres. Jiménez, Reyes, Sembradoras de futuros, p. 171.

${ }^{35}$ Testimonio de María Elena Rodríguez: “Con la Unión participé en el Movimiento del 68, en la marcha del silencio, estuvimos con los padres de los estudiantes, con los familiares de los presos políticos [...] Participé en el Movimiento del 68 tanto como miembro de la unmm, así como del Partido Comunista Mexicano". Testimonio de Leticia Montes: "En la CNED y en el Movimiento estudiantil del 68 participamos en igualdad de circunstancias con nuestros compañeros, sesionando hasta altas horas de la noche, cosa insólita para las mujeres y más todavía en los años sesenta, en una sociedad autoritaria donde las mujeres no podíamos salir ni a la esquina sin el permiso del papá o del hermano o del hombre de la familia; sin embargo, participamos en igualdad de circunstancias, discutíamos con ellos en las reuniones, llegábamos a acuerdos, distribuíamos propaganda, pintábamos paredes, estábamos en los mítines, éramos oradoras". Ambos testimonios en Jiménez, Reyes, Sembradoras de futuros, pp. 154 y 198. 
La UNMM incluso tomó la determinación de difundir las demandas del movimiento por medio de la emisión y distribución de panfletos y volantes que arengaban a las madres mexicanas:

\begin{abstract}
¡Basta ya de permitir que asesinen impunemente a nuestros hijos! Ha llegado el momento en que las madres tenemos que tomar su defensa. Ayudemos al pueblo y a los estudiantes en su justa lucha contra la represión formando comités de madres para manifestar nuestro apoyo; haciendo colectas para ayudar al Comité Nacional de Huelga; pidiendo el cese de la brutal represión gubernamental en contra del pueblo de México. Cada golpeado, cada herido, cada preso es hijo nuestro, porque es hijo del pueblo mexicano. ¡Defendamos a nuestros hijos! ¡Alto a las bayonetas! ${ }^{36}$
\end{abstract}

La coyuntura movilizadora fue vista por la UNMM como una ventana de oportunidad para auspiciar los llamados grupos cívicos, que se pretendían establecer por todo el territorio nacional mediante un llamamiento a todas sus afiliadas, a sus simpatizantes y a todas las mexicanas "en defensa de las Garantías Constitucionales y por la democracia en nuestro país"; y con los declarados objetivos de crear y fomentar la conciencia y la solidaridad ciudadanas. ${ }^{37}$ Estos embriones de novedosa ciudadanía, que podríamos calificar de génesis del poder popular con liderazgo y presencia femenil, deberían constituirse a partir del "Llamamiento" realizado por la UNMm bajo la consigna "¡Organiza tu grupo cívico!”, en los barrios, en las colonias, en los ejidos, en las fábricas, en las escuelas, en los núcleos comunitarios, etcétera. Los grupos cívicos - constituidos con unos ocho miembros cada uno- desarrollarían sus funciones teniendo delante la Constitución de 1917, con la pretensión de ejercer los derechos fundamentales concedidos en su articulado.

${ }^{36}$ Volante citado en Jiménez, Reyes, Sembradoras de futuros, p. 203.

${ }^{37}$ Jiménez, Reyes, Sembradoras de futuros, pp. 203-204. 
Aun con esta postura democrática reformista, y hasta si se quiere, de carácter utópico, los grupos cívicos revelarían el objetivo de la UNMM de acrecentar eventualmente su agencia en los ámbitos locales; lo que a la vez le representaría grandes desafíos al procurar difundir:
...los problemas más graves y urgentes de nuestro país, por lo que los grupos deberían estar al día de los acon- tecimientos a través del estudio colectivo de las noti- cias y documentos, además, era necesario que se estu- diara la historia de México y la Constitución. El Grupo Cívico debía dar a conocer también los problemas de su comunidad y divulgar los documentos del movimiento democrático a través de copias escritas a máquina o en mimeógrafo. También tendrían que establecer contacto con otros grupos y otras organizaciones. ${ }^{38}$

En el marco de este activismo femenil que efectivamente tendió lazos solidarios, quiero subrayar cómo la UNMM condenó enérgicamente el allanamiento realizado por elementos del ejército y del cuerpo de granaderos a las instalaciones de la Escuela de Arte Dramático del Instituto Nacional de Bellas Artes (INBA), el 31 de julio. Hecho también poco conocido porque tuvo lugar un día después de la ofensiva que el ejército concretó en el centro de la Ciudad de México, al tomar el edificio del Antiguo Colegio de San Idelfonso mediante un "bazucazo", que derrumbó su puerta, entonces sede de la Escuela Nacional Preparatoria, planteles 1 y 3.

En la Escuela de Arte Dramático, 73 personas, además de ser aterrorizadas con perros, fueron detenidas a la fuerza con armas largas. Entre ellas había 13 mujeres estudiantes y algunos profesores, incluyendo al director de la misma, José Solé. En la explanada del centro escolar se les hizo simulacro de fusilamiento. Todo el grupo

38 "Llamamiento" y Mujeres Mexicanas, México, núm. 9 (octubre-noviembre de 1968), p. 3, citados en Jiménez, Reyes, Sembradoras de futuros, p. 204. 
fue llevado con lujo de violencia a los separos de la Jefatura de Policía, acusado de tener filiación comunista y haber realizado ese 31 de julio una asamblea en la que había tomado partido en favor de los estudiantes de las vocacionales del Instituto Politécnico Nacional (IPN) y de las preparatorias de la UNAM, reprimidos al inicio del movimiento. A dichas acusaciones se agregaron la supuesta propaganda "subversiva" y los "libros tendenciosos de autores soviéticos", que el ejército y los granaderos habían localizado durante el cateo a las aulas de la Escuela. ${ }^{39}$

Las y los profesores de la Escuela de Arte Dramático del INBA suscribieron un pronunciamiento público rechazando rotundamente el allanamiento por parte de las fuerzas públicas. ${ }^{40}$

De igual manera, la UNMM, a un mes de dicho atropello, y en respaldo y solidaridad con el plantel, se pronunció en favor de quienes integraban el alumnado y el cuerpo docente de la Escuela de Arte Dramático, y condenó enérgicamente el uso excesivo de la violencia por parte de las fuerzas policiacas y el ejército. Pero el pronunciamiento de la UNMM fue más allá, pues se dirigió a toda la nación con la finalidad de que fuera entendido como una respuesta al Cuarto Informe Presidencial de Gustavo Díaz Ordaz (quien había declarado que quienes agredían a la sociedad eran los estudiantes, tergiversando la realidad al estigmatizarlos como pandilleros). ${ }^{41}$ La UNMM insistió, además, en la falta de libertades democráticas y demandó el freno de la generalizada represión. Éste fue especialmente un acto de deliberada subversión frente al Estado autoritario, que mostró la gran enjundia del movimiento femenil.

${ }^{39}$ Véase García Cárdenas, "Una mirada desde el poder: el movimiento estudiantil de 1968 en la lente de Manuel Gutiérrez Paredes", especialmente el capítulo IV "Fotografía e historia oral. Detención de los estudiantes de la Escuela de Arte Dramático del INBA en julio de 1968", pp. 169-196.

${ }^{40}$ Véase el pronunciamiento en el periódico El Día, México, 2 de agosto de 1968. Reproducido en Ramírez, El movimiento estudiantil de México, pp. 183-184.

${ }^{41}$ Véase el mensaje del cuarto informe presidencial de Gustavo Díaz Ordaz, 1 de septiembre de 1968. 
Sobre todo, la unMm puso el acento en que las mujeres estudiantes involucradas en el movimiento estudiantil estaban siendo objeto de prácticas represivas, y, especialmente, las alumnas de la Escuela de Arte Dramático, quienes habían sido agredidas con lujo de fuerza.

En representación de las mujeres miembros de la Unión Nacional de Mujeres Mexicanas y en representación de las mujeres a quienes hemos visto sufrir graves daños en estos días, [afirmamos] que sí hemos sido soezmente vejadas; que sí hemos sido injuriadas; que sí hemos sido ofendidas de palabra y de hecho, amenazadas, detenidas injustamente, pero en ningún caso los culpables han sido los estudiantes, compañeros, hijos, hermanos nuestros; quienes nos han golpeado y atropellado han sido el ejército y los miembros de las fuerzas represivas que se desataron desde fines de julio sobre los estudiantes y el pueblo capitalino [...]. Como madres, como mujeres, como ciudadanas mexicanas y como miembros de la Unión Nacional de Mujeres Mexicanas, rechazamos la calumnia contra el estudiantado, patentizamos una vez más nuestro decidido apoyo y solidaridad con el movimiento, y esperamos la justa solución de las demandas planteadas. ${ }^{42}$

La coyuntura del 68 fue muy significativa en la trayectoria de la UNMM y es una historia que ha estado francamente olvidada en los anales de la movilización estudiantil. En una explicación más encauzada para dimensionar su transgresión, se ve a las mujeres del 68 interpelando de distintas formas el orden social, jurídico y

42 "Carta pública de la unMm", publicada en Gaceta. Boletín Informativo del Comité Coordinador de Huelga de la UNAM, México, núm. 6, 7 de septiembre de 1968, reproducida en Ramírez, El movimiento estudiantil de México, pp. 289-290. 
político heteronormativo (jerarquizado y dicotómico) de la sociedad (por ejemplo, se desapegaron de conductas tradicionalistas y conservadoras) y rompieron con moldes femeninos estereotipados (como la abnegación y la resignación). También se les vio interesadas por la problemática estudiantil del periodo. Sus iniciativas y acciones fracturaron en el nivel simbólico barreras psicosociales. Sobre todo, en las mujeres de capas medias trabajadoras y estudiantiles, su experiencia en el movimiento las dotó de mayor conciencia social y política.

Madres, hermanas y esposas de los estudiantes detenidos, acompañadas de las propias estudiantes (muchas de ellas brigadistas), marcharon el lunes 30 de septiembre desde el Monumento a la Madre y por el Paseo de la Reforma, siguiendo el trayecto de la Avenida Juárez, hasta desembocar en la Cámara de Diputados en el centro histórico de la Ciudad de México.

El contingente fue convocado por la UNMM mediante volantes distribuidos por toda la ciudad capital, y se engrosó a lo largo del camino hasta sumar cinco mil mujeres, muchas de ellas madres de familia (trabajadoras, oficinistas, campesinas, intelectuales, maestras, profesionistas, artistas, amas de casa), pero también estudiantes varones, padres de familia y gente del pueblo, incluso niños, niñas y mujeres de avanzada edad llevando pancartas. Todas y todos exigiendo libertad a los presos políticos y declarando su solidaridad con la movilización estudiantil. La descubierta de la marcha llevaba dos grandes mantas: una, exigiendo diálogo, y no a las bayonetas, con una imagen de una madre y un estudiante, así como con grandes letras: Unión Nacional de Mujeres Mexicanas, expresando con ello, vivamente, su carácter de género con acentuación maternalista. La otra manta tenía la leyenda: "El diálogo es el vehículo de la inteligencia, mas no las bayonetas". También se portaba una bandera nacional con un crespón negro en señal de duelo por los estudiantes caídos. En tanto, ante los reclamos de las y los manifestantes, fueron ubicados cordones policiacos para amedrentar a mujeres y hombres.

Frente a la Cámara de Diputados, en la calle de Donceles, se escuchó la voz de la UnMm por medio de su vocera, Dolores Sotelo, 
comunista de larga trayectoria, quien testimonió la solidaridad de las mujeres afiliadas a la UnMm "con la lucha estudiantil". También tomaron la palabra madres de familia exigiendo el cese de la represión y el cumplimiento del pliego petitorio del Consejo Nacional de Huelga (CNH). Además, se levantaron los puños para hacer la $\mathrm{V}$ de la victoria, se guardó un minuto de silencio y se cantó el himno nacional.

Fue especialmente emotiva la intervención de la madre de Luis Lorenzo Ríos, estudiante asesinado por las fuerzas policiacas, quien asentó: "Les habla una madre que ya no lo es. Una madre de uno de los jóvenes muertos el lunes en Santo Tomás. Aquí está una madre con los brazos abiertos que no tiene ya más hijos, pero que está dispuesta también a dar su vida para que en México haya libertad". ${ }^{3}$

En su Crónica 1968, Daniel Cazés explica el objetivo buscado por las y los miles de manifestantes: "Se pidió la presencia de diputados, para entregarles una solicitud de amnistía para los presos políticos, y la exigencia del restablecimiento del orden, respeto a la Constitución, fin de detenciones y consignaciones ilegales, y salida del ejército de los centros educativos". 44

Fue recibida una comisión de madres de familia en el interior del recinto legislativo. Se sabe que con evasivas fueron atendidas por diputados priistas, sin que realmente se diera solución a sus exigencias, pues la masacre del 2 de octubre en Tlatelolco estaba a punto de desencadenarse.

Es importante subrayar los marcos de acción colectiva mediante los cuales se desplazaron miles de mujeres en el verano del 68, y como parte de la movilización a la que convocó la UnMM, porque:

${ }^{43}$ Jiménez, Reyes, Sembradoras de futuros, p. 202. Véase el recuento gráfico de la marcha en García Cárdenas, "Una mirada desde el poder: el movimiento estudiantil de 1968 en la lente de Manuel Gutiérrez Paredes". Sobre todo, el apartado "La Unión Nacional de Mujeres Mexicanas ante la Cámara de Diputados (30 de septiembre de 1968)", pp. 100-106.

${ }^{44}$ Cazés, Crónica 1968, p. 207. 
...hacía muchos años que en nuestro país no se realizaban actos de carácter combativo organizados por las mujeres, demostrando así que su participación da[ba] un carácter vigoroso a las luchas femeniles [de los años sesenta en México]. ${ }^{45}$

A pesar de sus firmes exigencias y demandas, en la solución al conflicto no habría, de ninguna manera, ni justicia ni democracia. En el post 68, la unmm, en voz de Martha López Portillo de Tamayo, ${ }^{46}$ exigió el 31 de octubre, ante el subprocurador del Distrito, José Dzib Cardoso, que fuesen excarceladas mujeres que habían sido presas el 2 de octubre en Tlatelolco: Rina Lazo, Marcela Morales Alzate, Celia Sandoval de Correa, Adela Salazar de Castillejos, Amada Velasco Torres, Mika Seeger, Guadalupe Salazar Gómez, Margarita Urías Hermosillo y Teresa Lonfreno. Incluso se pidió la libertad de Ana María Rico Galán y de María del Carmen Hermosillo, quienes tenían ya dos años de encierro. ${ }^{47}$

Al mismo tiempo, las dirigentes de la UnMm se presentaron el 4 de noviembre de ese año en un debate público organizado por la Cámara de Diputados en torno del artículo 145, el llamado "delito de disolución social”. Después de presentar un análisis jurídico legal, aseguraron que dicho artículo era anticonstitucional,

45 "Declaración de la UnMm", en Mujeres Mexicanas, México, núm. 9 (octubre-noviembre de 1968), citada en Jiménez, Reyes, Sembradoras de futuros, p. 202.

${ }_{46}$ Martha López Portillo de Tamayo asumió la presidencia de la Unmm en septiembre de 1967, en el marco del Primer Congreso Nacional Ordinario, luego de que Clementina Batalla de Bassols se retiró de sus funciones y fue reconocida su amplia trayectoria. Batalla de Bassols y Eulalia Guzmán fueron investidas como presidentas de honor de la organización femenil. Véase Jiménez, Reyes, Sembradoras de futuros, p. 178.

${ }^{47}$ Mujeres Mexicanas, núm. 9, México, octubre-noviembre de 1968, p. 7, citado en Jiménez, Reyes, Sembradoras de futuros, p. 205. 
...en cuanto a que restringe el derecho de libertad de reunión consagrado en el Artículo $9^{\circ}$ y la libertad de pensamiento estatuida por el Artículo $6^{\circ}$ ¿Por qué mantenerlo? [se preguntaban]. Por [lo tanto], pedimos al Poder Legislativo de nuestro país, la derogación del Artículo 145 del Código Penal Federal.

De igual manera esta exigencia se sumó a una batería de derechos políticos que enlistaba la UNMM como permanentemente conculcados para las mujeres, dejándolas en un plano secundario y sin equidad frente a un orden social hegemónico y antidemocrático de carácter varonil. ${ }^{48}$

La violencia política y el terrorismo de Estado desplegados por los gobiernos de Gustavo Díaz Ordaz y Luis Echeverría Álvarez - una de cuyas muestras era precisamente el mantenimiento de aquella normativa jurídica que afectaba a mujeres y hombres por igual - serían la piedra de toque con la que se cerraría esa década y con la que se abriría también la siguiente. Cientos de mujeres y hombres del 68 verían cerradas las vías del diálogo y la participación democrática, y acabarían en las filas de la guerrilla mexicana ${ }^{49}$ de la segunda mitad del siglo xx.

${ }^{48}$ Mujeres Mexicanas, México, núm. 10 (febrero-marzo de 1969), pp. 6 y 8-9, citado en Jiménez, Reyes, Sembradoras de futuros, pp. 205-207. Desde su fundación, la unMm repudió el artículo 145, que vulneraba fuertemente la efectividad de sus derechos políticos: "Pugnar porque la mujer actúe decididamente en defensa de los derechos constitucionales tales como: derecho de asociación y de reunión; libertad de pensamiento y de expresión; por la derogación de todo ordenamiento que viole esos derechos, tales como el artículo 145 del Código Penal [...]; demandar para las mujeres los mismos derechos políticos que para los hombres, sin discriminación, para ocupar puestos públicos y de elección popular; luchar por una representación auténtica y libremente elegida por el pueblo mexicano". Jiménez, Reyes, Sembradoras de futuros, p. 122.

${ }^{49}$ Se desconoce a la fecha el papel jugado por la UNMM en su mediación y apoyo a las organizaciones de familiares de presos y desaparecidos políticos derivados de la Guerra Sucia del Estado mexicano contra las organizaciones político militares. Escuetamente se sabe que la dirigencia de la UNMm contactó a Rosario Ibarra de Piedra. Jiménez, Reyes, Sembradoras de futuros, p. 167. 


\section{Consideraciones finales}

A pesar de las evidentes restricciones y cortapisas que tuvieron las mujeres para el acceso pleno al ejercicio de la política y a la movilización social a lo largo del siglo xx, el activismo de las mexicanas de izquierda fue parte de una participación y una cultura política alternativas que dieron realce a su papel político, es decir, sus marcos de acción colectiva femenil cuestionaron implícita y explícitamente el enclaustramiento femenino en la esfera cultural tradicional del hogar y el trabajo doméstico. Particularmente, la UnMm se decantó por un giro igualitarista (con acciones en asociación con sus congéneres varones $)^{50}$ y fomentó un discurso unionista femenil para que masivamente las mujeres de todos los sectores concretaran una organización amplia y de carácter nacional en defensa de los derechos de las mexicanas. ${ }^{51}$ No fueron menos importantes los idearios de la UNMM para construir sociedades más igualitarias desde sus ópticas maternalistas (con acento social, político, laboral, educativo, de salud, etcétera), aunque podría discutirse si su pensamiento maternal retrasó, detuvo o neutralizó el proceso de la emancipación femenina.

A la vez, el feminismo de esas mexicanas confrontó los estigmas sexistas de que eran objeto de manera cotidiana, aun por parte de sus camaradas de izquierda. Es muy elocuente el testimonio de Ruth

\footnotetext{
${ }^{50}$ La UNMM se propuso realizar acciones al lado de organizaciones obreras y populares de extracción varonil "para intervenir en todos los casos en que se amenazaran los intereses de la familia (despido de los trabajadores, bajos salarios [carestía de la vida], negación de la tierra, créditos y agua, maniobras contra la venta de cosechas, represión y persecución de los esposos, y otras)". Jiménez, Reyes, Sembradoras de futuros, pp. 176-177.

${ }^{51}$ La UNMM acordó reiteradamente "propiciar e intensificar la colaboración con todas las organizaciones sociales afines y amigas, así como con aquéllas con las que coincidamos, así sea en un solo punto de nuestros objetivos, con el fin de realizar acciones comunes y unificadas en beneficio de la mujer y de la infancia”. Jiménez, Reyes, Sembradoras de futuros, p. 178.
} 
Golberg, miembro de la UnMm, porque refleja la concepción que de las mujeres se tenía, incluso dentro del PGM: ${ }^{52}$

Me peleaba siempre con los compañeros porque nos vacilaban, nos pusieron el nombre de las UVAS, que significaba "unión de viejas argüenderas", en vez de Unión Nacional de Mujeres Mexicanas. Sin embargo, nos tenían que tomar en cuenta porque trabajábamos bastante. En una forma más amplia llegábamos a más y más mujeres entre el movimiento popular que el mismo partido; llegábamos a los oídos de mujeres para desarrollar su nivel político... ${ }^{53}$

Por otro lado, las condiciones de la crisis bipolar internacional las orillaron también a una presencia más activa en sus adhesiones a la Cuba revolucionaria y al pueblo de Vietnam, entre otras. Así como sus voluntades y enfoques para que las mujeres del planeta accedieran a un mundo sin tribulaciones por el estado continuo de conflictos bélicos y al borde de una verdadera catástrofe nuclear.

Especialmente, la invisibilidad y el olvido de los contingentes femeniles de la UNMm en la coyuntura tan relevante del 68, forman parte de la "tendencia a desvalorizar tareas o formas de comportamiento solo porque son femeninas", y son resultado "de los componentes patriarcales de la sociedad", que han fomentado modelos tradicionales de feminidad. Implícitamente, al poner de relieve a los grupos femeniles a los cuales he hecho referencia, de alguna manera interpelo "las concepciones teóricas utilizadas hasta hoy,

${ }^{52}$ Aunque el PCM se asumió como una organización de izquierda, generalmente su dirigencia y su militancia se conducían bajo esquemas preconcebidos inequitativos y machistas. Se ha documentado cómo la formación de izquierda fue copartícipe y reproductora de las normas de género socialmente hegemónicas. Oikión Solano, "Mujeres comunistas en México. Desigualdad social y lucha política, 19351955”, pp. 153-172.

${ }^{53}$ Jiménez, Reyes, Sembradoras de futuros, p. 167. 
para eliminar sus sesgos androcéntricos". ${ }^{54}$ A la par, se puede apreciar que durante el conflicto estudiantil las mujeres tendieron a "ser importantes difusoras informales [...] a través de sus redes cotidianas más cercanas, [realizando] un importante papel de sensibilización y movilización", ${ }^{55}$ destacando su contribución al movimiento popular desde su posición de género. Si bien el propio movimiento no tuvo una exclusiva vertiente para atender o debatir de manera específica los problemas de las mujeres en su particular condición.

Empero, al concluir constato las apreciaciones de Hernández Martínez, acerca de que: "el género influye en aspectos como la movilización, los patrones de liderazgo, las oportunidades políticas, las estrategias, las estructuras organizativas, las ideologías e incluso los posibles impactos de un movimiento social". ${ }^{56}$

Por ende, no me queda más que unirme a la postura esgrimida por la socióloga Judith Astellarra, quien de manera contundente aspira a la profundización de los marcos democráticos, pues éstos siempre se mantendrán incompletos "si un colectivo tan grande como el femenino está excluido y [si] sus intereses y [sus] valores están ausentes".57

${ }^{54}$ Astelarra, "La cultura política de las mujeres", pp. 167-168.

${ }^{55}$ Hernández Martínez, "Las formas de acción colectiva: partidos políticos y movimientos sociales", pp. 156-157.

${ }^{56}$ Hernández Martínez, "Las formas de acción colectiva: partidos políticos y movimientos sociales", p. 152.

${ }^{57}$ Astelarra, "La cultura política de las mujeres", p. 168. 


\section{Fuentes}

\section{Archivos y repositorios documentales}

AGN Archivo General de la Nación de México.

Biblioteca del Museo Nacional de Antropología e Historia. Programa de Historia Oral del INAH.

\section{Bibliografía}

Astelarra, Judith, "La cultura política de las mujeres", en Norbert Lechner (comp.), Cultura politica y democratización, Santiago de Chile, ClacSO-Flacso-Instituto de Cooperación Iberoamericana, 1987, pp. 149-168.

Barrancos, Dora, "Maternalismo", en Susana Gamba (coord.), Diccionario de estudios de género y feminismos, $2^{\mathrm{a}}$ ed., Buenos Aires, Biblos, 2009, pp. 207-208.

Bustamante Méndez, Guadalupe Belem, "Las Memorias de Clementina Batalla de Bassols (1894-1987). Pensamientos tomados de aquí y allá y recuerdos de mi vida", tesis de licenciatura inédita en historia, México, Facultad de Filosofía y Letras-Colegio de Historia de la UnAM, 1996.

Cazés, Daniel, Crónica 1968, México, Plaza y Valdés Editores, 1993.

Guarto Informe Presidencial de Gustavo Díaz Ordaz, wrerw.biblioteca. to/artman2/publish/1968_87/Mensaje_del_Cuarto_Informe_que_rindi_ al_H_Congreso_293.shtml[consultado el 17 de junio de 2018]. 
García Cárdenas, Oralia, "Una mirada desde el poder: el Movimiento Estudiantil de 1968 en la lente de Manuel Gutiérrez Paredes", tesis de licenciatura en Historia, inédita, México, ENAH-INAH, 2014.

Haan, Francisca De, "La Federación Democrática Internacional de Mujeres (FDIM) y América Latina, de 1945 a los años setenta”, en Adriana Valobra y Mercedes Yusta (eds.), Queridas Camaradas. Historias iberoamericanas de mujeres comunistas, Buenos Aires, Miño y Dávila Editores, 2017, pp. 17-44.

Hernández Martínez, Eva, "Las formas de acción colectiva: partidos políticos y movimientos sociales", en Marta Lois, Alba Alonso (coords.), Ciencia política con perspectiva de género, Madrid, Akal, 2014 (Akal Textos, 38), pp. 129-159.

Hernández Sandoica, Elena, Tendencias historiográficas actuales. Escribir historia hoy, Madrid, Akal, 2004 (Akal Universitaria. Serie Historia contemporánea, 234).

Jiménez Álvarez, Ana Victoria, y Francisca Reyes Castellanos, Sembradoras de futuros. Memoria de la Unión Nacional de Mujeres Mexicanas, México, Unión Nacional de Mujeres Mexicanas, 2000.

Nava Hernández, Eduardo, "El cardenismo en Michoacán (19101990)", tesis inédita de doctorado en ciencia política, México, Facultad de Ciencias Políticas y Sociales de la unam, 2003.

Oikión Solano, Verónica, Cuca García (1889-1973), por las causas de las mujeres y la revolución, Zamora, El Colegio de Michoacán-Centro de Investigaciones y Estudios de Género de la unam-El Colegio de San Luis, 2018. 
, "El Movimiento de Liberación Nacional en Michoacán, 1961-1964", ponencia presentada en el XIV Congreso Nacional de Estudios Electorales, organizado por la Sociedad Mexicana de Estudios Electorales, A.C., Puerto de Mazatlán, Sinaloa, 8-10 de octubre de 2002, 31 pp.

, "La Central Nacional de Estudiantes Democráticos, una historia de militancia juvenil", en José René Rivas Ontiveros, Ana María Sánchez Sáenz, Gloria A. Tirado Villegas (coords.), Historia y memoria de los movimientos estudiantiles. A 45 años del 68, 2 vols., México, unam-Buap-Ediciones Gernika, 2017, vol. 2 "Los movimientos estudiantiles regionales en México", pp. 105-133.

"Mujeres comunistas en México. Desigualdad social y lucha política, 1935-1955", en Adriana Valobra, Mercedes Yusta (eds.), Queridas Camaradas. Historias iberoamericanas de mujeres comunistas, Buenos Aires, Miño y Dávila Editores, 2017, pp. 153-172.

Pieper Mooney, Jadwiga E., "El antifascismo como fuerza movilizadora: Fanny Edelman y la Federación Democrática Internacional de Mujeres (FDIM)", en Anuario IEHS, núm. 28, 2013, pp. 207-226.

Ramírez, Ramón, El Movimiento Estudiantil de México. Fulio-diciembre de 1968, México, Ediciones Era, 1969, tomo I Análisis/Cronología.

Tarrow, Sidney G., El poder en movimiento. Los movimientos sociales, la acción colectiva y la política, $3^{\mathrm{a}}$ ed. (trad. Francisco Muñoz de Bustillo), Madrid, Alianza Editorial, 2012.

Wilkie, James y Edna Wilkie, "Entrevista a Clementina Batalla de Bassols", http://www.profmex.org/mexicoandtheworld/ volume13/4fall08/clementina.html [consultado el 26 de mayo de 2017]. 